\title{
Industrial Sector Input Demand Responsiveness and Policy Interventions
}

\author{
MuHAmmad Ali Chaudhary, EATZAZ Ahmad, ABID A. BurKi, \\ and MUSHTAQ A. KHAN
}

\section{INTRODUCTION}

In Pakistan, government intervention in the input market of the industrial sector is considerable. It regulates prices of virtually all energy and certain other non-labour inputs. To stimulate industrial production and output growth, it also encourages the provision of extended credit facilities to the industrial producers. Further, it has also often announced adjustments/reductions in duties and tariffs on products used in industrial production. Conversely, government also imposes taxes on outputs. It may desire to levy new taxes on the industrial inputs. All interventions have profound implications for producers, consumers and the government alike. Therefore, it is important to know how they may affect the industrial input demand. Further, it is equally important to know how effective they may be for the government in the realisation of its objectives. The most pertinent approach to ascertain the industrial input demand responsiveness to government interventions is to obtain valid estimates of price elasticities. In fact, competent elasticity estimates of the producer input demand derived with a sound methodology can serve as a solid basis to predict producer responsiveness to market changes and thereby the effectiveness and desirability of government interventions.

While the price elasticities of products over the years have been estimated for Pakistan, renewed interest on estimating responsiveness of producer input demand with modern estimation procedures has recently surged. Idrees (1997) and Khan (1998) have determined elasticities for the domestic large-scale manufacturing sector from a demand system. Although these research studies make a good addition to the literature, their scope is extremely limited because they have combined industrial inputs into large aggregates. At present, there is no study that has investigated the input demand elasticities of the domestic industrial sector at the dis-aggregated level. It is known that the pricing and other decisions are taken for each industrial input separately though not

\footnotetext{
Muhammad Ali Chaudhary, Eatzaz Ahmad and Abid A. Burki are Professors of Economics, and Mushtaq A. Khan is Assistant Professor of Economics at Quaid-i-Azam University, Islamabad.

Authors' Note: This article is based on a section of a research project financed by the Planning and Development Division. The authors are very thankful to the Division for providing financial support for the project.
} 
entirely in isolation of other required inputs. Thus, this study estimates the input demand elasticities for the large scale manufacturing sector of Pakistan for each input separately. Further, necessary estimation is performed with a flexible profit function in the framework of an input demand system. ${ }^{1}$

\section{ESTIMATION OF INDUSTRIAL INPUT DEMAND ELASTICITIES}

\section{Specification of Input Demand System}

The demand elasticities of a range of energy inputs like electricity, natural gas, petroleum products, coke and coal, and firewood along with labour, capital and output are derived by estimating an input demand system. Since the demand system used is based on certain behavioural assumptions, it is considered necessary to explain those assumptions and the characteristic nature of the elasticities derived before representing the system or the model in detail.

\section{Behavioural Assumptions and the Nature of Elasticities}

The elasticity of demand for an input provides a unit-free measure of the degree of responsiveness of the quantities demanded to a given percentage change in its ownprice or in other related variables like the prices of other inputs, output price or output level. Although the concept of elasticity as such is quite familiar, yet in practical application one has to choose from a variety of ways elasticity can be measured, depending on the assumptions one makes about the behaviour of decision-making units, which in this case are industrial producers or firms.

The behaviour of a firm depends on the objective it pursues when taking a decision on the level of production and input mix. Yet, almost all the economic objectives of a firm can be fitted into the general framework of profit-maximisation. The behaviour may differ across firms due to various constraints. These constraints can be classified into three broad categories: technological constraints, market constraints and financial constraints. The most obvious technological constraint is given by the production function that determines options of combining various inputs to produce any given level of output. Market constraints refer to the ability of a firm to influence market outcomes such as the prices of output and inputs. For example, a competitive firm is constrained to sell its output at a price that is out of its control, while a firm with monopoly power must choose a price-output combination on the demand curve it faces. Similar constraints apply in the input markets. Financial constraints further limit the range of options available to a firm. When uncertainty, high transaction costs, etc. render capital markets imperfect a firm may not be able to finance the cost of achieving its optimal level of production. Financial constraints can limit a firm's long-run expansion in its production.

\footnotetext{
${ }^{1}$ See Diewert $(1973,1976)$ and Deaton and Muelbauer (1980) for superiority of a system approach over single equation method for such research efforts.
} 
The firms' optimisation problem of a firm requires certain conditions to be solved to determine the profit maximising input demand functions. The substitution of these demand functions into the production function yields the profit-maximising output supply function. The substitution of output supply and input demand functions into the profit equation, in turn, yields the profit function. Furthermore, it is also possible to trace back to all the other functions from the profit function by using duality theorems [Varian (1992)]. For example, the use of the Hotelling Lemma permits to derive the output supply and input demand functions from the profit function. Finally, by using the inverse of the input demand functions so obtained, under certain conditions, one can also go back to the production function on the basis of the integribility theorem.

The above optimising problem can be restricted to cost minimisation if output level is pre-determined, and to revenue maximisation if the output total cost is fixed at a certain level. These optimisation problems can be solved to derive input demand functions and, subsequently, the cost or revenue function. Again, the duality relation given by Shephard's Lemma and Roy's identity can be used to trace the input demand functions from the cost or revenue function. As in the profit maximisation problem, we can use the integribility theorem to trace the underlying production function from the inverse input demand functions [Diewert (1974); McFadden(1978) and Varian (1992)].

Various duality relations and other linkages across production, profit, cost and revenue functions have extensively been used in recent improved empirical modelling of the firm theory. The development of many flexible functional forms has been possible only due to these duality relations. However, the empirical study of duality relationships is possible only with some restricted forms of the function that are explicitly specified at the outset. If, for example, the production function has a complicated functional form, it may not be possible to find an explicit solution for the input demand function. However, even in this case, most of the properties of the input demand function can be established as is commonly done with a general production function [Varian (1992)].

It follows from the above that most of the information on production technology and a firm's behaviour can be obtained whether one starts with a production function, a profit function, a cost function or a revenue function. One of the pertinent issues then is the choice of the starting point. The generally established wisdom is to choose a starting point that provides an easier approach to input demand functions and is, at the same time, flexible enough to make the empirical exercise worthwhile.

Given that all essential information on technology is readily available from any one of the profit, cost and revenue functions with the help of duality relations, there is no specific advantage in assuming an explicit form of production function, while there are many disadvantages. First, only in the case of highly restrictive production function such as Cobb-Douglas or CES, one can find an algebraic solution to the optimisation problem to yield input demand functions. It is well known that in such cases the elasticity estimates would be severely restrictive. Another problem in estimating a production 
function is that with the limited sample size usually available, the estimated parameters are likely to be statistically imprecise [Christensen, Jorgenson and Lau (1971)]. For these reasons and, especially, the fact that the estimation of a system of input demand functions provides more efficient information than the estimation of a single production function, the direct estimation of input demand system has flourished in recent empirical literature. This practice has also extended the choice of new functional forms.

The next question is as to what underlying behavioural assumptions are most appropriate in specifying the input demand functions. Since the ultimate objective of the present analysis is to estimate elasticities of input demands, the choice depends mainly on the nature of elasticities required. The revenue maximisation approach is the least popular in empirical literature because it does not provide as much direct information on the various characteristics of production technology, such as elasticity of substitution, as is possible from the cost function. Besides, from the long run perspective, the assumption of financial constraint that would limit a firm's total cost is not very convincing.

Of the remaining two approaches, the profit maximisation approach is preferable to the cost minimisation approach for two main reasons, though the former also has certain limitations. ${ }^{2}$ An obvious advantage of profit-maximisation approach is that it also enables estimation of the elasticities of input demand with respect to output price. This information is useful in assessing the effects of alternative tax packages, especially the general sales tax (GST), which is also referred to as goods and services tax that alters the prices of all the products whether they are used as inputs or as outputs. ${ }^{3}$

Another reason for preferring the profit maximisation approach is that it gives conceptually more accurate estimates of cross elasticities between various inputs. The cross elasticities estimated from the cost function, which are called Hicksian or compensated elasticities, are biassed towards classifying inputs as substitutes. Due to the homogeneity of input demands with respect to input prices, the own and all the cross elasticities of demand for each input sum to zero. Since the own elasticity is always negative, the cross elasticities must sum to a positive number, except in case of Leontief technology wherein all the own and cross elasticities are equal to zero. Thus, in a twoinput system, the cross elasticity is always positive. In case of more than two inputs, all the cross elasticities can be positive, but they cannot all be negative or zero.

Elaborating the basic weakness in compensated price effect in the context of consumer theory with additive preferences, Houthakkar (1960) has decomposed the compensated price effect into two components, namely the 'specific effect' and the 'general effect'. The specific effect is conditional on constant marginal utility, whereas the general effect results from the change in marginal utility necessary to keep the total

\footnotetext{
${ }^{2}$ Profit maximisation approach has the weakness that it assumes that firms under study face no financial or sales constraints. Furthermore, it is also necessary to specify the structure of the markets where the firms are operating.

${ }^{3}$ Because of this property, the GST is also known as value added tax.
} 
utility constant when the price of a good rises. While the specific cross effect can be positive or negative, the general cross effect is always positive, thereby introducing upward bias in the cross compensated effect. ${ }^{4}$ Browning et al. (1985) have shown that the specific own and cross price effects are the same as the own and cross price effects in Frisch (1932) demands, which are analogous to input demand under profit maximisation behaviours. ${ }^{5}$ Basically, this means that the cross elasticities obtained from the profit maximising input demands have no inherent bias in classifying a pair of inputs as substitutes or complements. In the light of these observations, the profit maximisation approach appears to be a more appealing behavioural assumption.

\section{Specification}

In specifying the profit function, our main consideration is to satisfy three requirements. The first is that the specified profit function should be internally consistent. In particular, it should not contradict the very basic assumption that the decision-making units do in fact maximise profit. This assumption leads to a number of well-known properties that the profit function and the associated output supply and input demand functions are supposed to satisfy. The second consideration is that the specification of profit function should not severely restrict the range of values that various parameters of interest, such as the elasticities of input demands, are allowed to take. The flexible functional form of profit function is desirable because it does not impose rigid assumptions on the range of such parameters. Finally, it is also desirable to choose a linear (in parameters) functional form because one can then ensure that the direct application of appropriate estimation technique would yield the Full Information Maximum Likelihood (FIML) estimates.

The translog profit function, which is the most popular functional form in empirical literature, satisfies the second criteria. Some of the conditions required for internal consistency can be imposed directly on the function, while the others have to be left as testable hypotheses. The translog function is a second order polynomial approximation in natural logs to the Taylor series representation of the unknown function. In general form, the translog profit function along with the input share and revenue share equations (using Hotelling Lemma) can be written as follows

$$
\begin{aligned}
& \ln \pi=\alpha+\sum_{i=1}^{n} \alpha_{i} \ln W_{i}+\alpha_{q} \ln P+\frac{1}{2} \sum_{i=1}^{n} \sum_{j=1}^{n} \gamma_{i j} \ln W_{i} \ln W_{j} \\
& +\frac{1}{2} \gamma_{q q}(\ln P)^{2}+\frac{1}{2} \sum_{i=1}^{n} \gamma_{i q} \ln W_{i} \ln P, \\
& \gamma_{i j}=\gamma_{j i}, \quad \gamma_{i q}=\gamma_{q i} \\
& \text {.. } \quad \cdots \quad \cdots
\end{aligned}
$$

\footnotetext{
${ }^{4}$ For more details on the subject see, Ahmad (1988) and Browning et al. (1985).

${ }^{5}$ Ahmad (1995a) has further extended the results to models of monopolistic behaviour.
} 


$$
\begin{array}{ccccc}
S_{i}=-\left[\alpha_{i}+\sum_{j=1}^{n} \gamma_{i j} \ln W_{j}+\gamma_{i q} \ln P\right] & \ldots & \ldots & \ldots & \ldots \\
S_{q}=\alpha_{q}+\sum_{j=1}^{n} \gamma_{q j} \ln W_{j}+\gamma_{q q} \ln P & \ldots & \ldots & \ldots & \ldots
\end{array}
$$

where $\pi, P$ and $W_{i}$ are profit, output price and the price of input $i$, respectively, $S_{i}$ is the profit share of cost on input $i$ and $S_{q}$ is the profit share of revenue.

The above specification does not in itself satisfy all standard properties required for internal consistency, though the property that the profit function is continuous in prices is satisfied. The second requirement is that the profit function is homogeneous of degree one in all prices, while the output supply and input demand functions are homogeneous of degree zero. These homogeneity properties along with the symmetry conditions yield the following restrictions. ${ }^{6}$

$$
\begin{array}{ccccccc}
\alpha_{q}+\sum_{i=1}^{n} \alpha_{i}=1 & \ldots & \ldots & \ldots & \ldots & \ldots & \ldots \\
\gamma_{i q}+\sum_{j=1}^{n} \gamma_{i j}=0 & \ldots & \ldots & \ldots & \ldots & \ldots & \ldots \\
\gamma_{q q}+\sum_{i=1}^{n} \gamma_{i q}=0 & \ldots & \ldots & \ldots & \ldots & \ldots & \ldots
\end{array}
$$

An obvious implication of these restrictions is that not all the input demand functions are independently identified. In other words, in a system of $n$ inputs, only $n-1$ input demand functions need to be estimated, while the parameters of the $n$th demand functions are retrieved residually by applying the above restrictions.

Two more properties that the profit function is supposed to satisfy cannot be directly imposed. One can, however, verify whether these properties hold in the estimated system of equations. The first of these properties, known as monotonicity or the slope condition, requires that the profit function is a monotonically increasing function of output price and monotonically decreasing function of input prices. By Hotelling's Lemma, this is equivalent to the requirement that the estimated values of all the shares are positive. The second property, known as convexity or curvature condition, is that the profit function is strictly convex in input prices, which also implies that the function is strictly convex in output price. Furthermore, the convexity of profit function also implies that the output supply function is the monotonically increasing function of output price, while each input demand function is monotonically the decreasing function of the own input price. These two properties require the monotonicity condition given by:

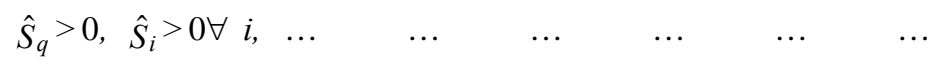

\footnotetext{
${ }^{6}$ These restrictions also follow from the adding-up condition requiring that the difference between the profit share of revenue and the profit share of inputs' cost is equal to one.
} 
and the convexity condition requiring the following Hessian matrix to be positive semidefinite, is written as

$$
\left[\begin{array}{rrrr}
\frac{\partial^{2} \hat{\pi}}{\partial W_{1}^{2}} & \frac{\partial^{2} \hat{\pi}}{\partial W_{1} \partial W_{2}} & \cdots \frac{\partial^{2} \hat{\pi}}{\partial W_{1} \partial W_{n}} \\
\frac{\partial^{2} \hat{\pi}}{\partial W_{2} \partial W_{1}} & \frac{\partial^{2} \hat{\pi}}{\partial W_{2}^{2}} & \cdots \frac{\partial^{2} \hat{\pi}}{\partial W_{2} \partial W_{n}} \\
\vdots & \vdots & \vdots \\
\frac{\partial^{2} \hat{\pi}}{\partial W_{n} \partial W_{1}} & \frac{\partial^{2} \hat{\pi}}{\partial W_{n} \partial W_{2}} & \cdots \frac{\partial^{2} \hat{\pi}}{\partial W_{n}^{2}}
\end{array}\right] \ldots \quad \ldots \quad \ldots
$$

The necessary and sufficient condition for convexity is that the principal minors of the Hessian matrix must alternate in signs as $H_{11} \leq 0, H_{22} \geq 0, H_{33} \leq 0$ and $H_{44} \geq 0$.

Since the translog profit function is a local approximation, it is possible that the monotonicity and/or curvature conditions are violated. If this happens, then the estimated parameters can yield absurd results such as positive estimates for the own elasticities of input demands. With flexible functional forms, the violation of these properties is not an uncommon observation, especially in a system containing a large number of inputs. However, one has to be concerned mainly with the practical implications of the violation of these properties. If some elasticities turn out to have 'wrong' algebraic signs but these are not significantly different from zero, this would mean that the violation of the curvature condition is tolerable in the sense that the elasticities with wrong signs can be regarded as being equal to zero in the statistical sense.

It is easy to verify that the elasticities of demand for input $i$ with respect to its own price, the price of another input and the price of output are, respectively, as follows:

$$
\begin{aligned}
& \sigma_{i i}=-\left(\begin{array}{lllllll}
1+S_{i}+\frac{\gamma_{i i}}{S_{i}} & \ldots & \ldots & \ldots & \ldots & \ldots
\end{array}\right. \\
& \sigma_{i j}=-\left(\begin{array}{cccccc}
\left.S_{j}+\frac{\gamma_{i j}}{S_{i}}\right), i \neq j & \ldots & \ldots & \ldots & \ldots & \ldots
\end{array}\right. \\
& \sigma_{i q}=-\left(\begin{array}{llllll}
S_{q}-\frac{\gamma_{i q}}{S_{i}} & \ldots & \ldots & \ldots & \ldots & \ldots
\end{array}\right.
\end{aligned}
$$

Likewise, the elasticities of output supply with respect to output price and the input prices are 


$$
\begin{array}{llllll}
\sigma_{q q}=-1+S_{q}+\frac{\gamma_{q q}}{S_{q}} & \ldots & \ldots & \ldots & \ldots & \ldots \\
\sigma_{q i}=-S_{i}+\frac{\gamma_{i q}}{S_{q}} & \ldots & \ldots & \ldots & \ldots & \ldots
\end{array}
$$

\section{THE ESTIMATION PROCEDURE, DATA AND CONSTRUCTION OF VARIABLES}

The profit function (1) along with the share Equations (2) and (3) are estimated by using capital, labour and 11 energy inputs. The energy inputs are electricity, natural gas, petrol, light diesel oil (LDO), high-speed diesel oil (HSDO), furnace oil (FO), kerosene oil (KO), charcoal, coke, coal and firewood.

The only reliable data source on the activities of manufacturing sector in Pakistan is the Censuses of Manufacturing Industries (CMI), which have been published irregularly for the years 1969-70, 1970-71, 1975-76 to 1987-88 and 1990-91. This gives a total of 16 annual observations. Since the profit function along with one output supply function and 12 independent input demand functions are estimated as a system, there are effectively $16 \times(1+1+12)=224$ observations to estimate the whole system. To gain further degrees of freedom, the province level data for Punjab and Sindh, where most of the manufacturing firms (more than 80 percent) are located, are pooled. This practice has also been adopted successfully in a number of other studies such as by Battese and Malik (1987); Idrees (1997); Khan (1998) and Malik (1989). Research studies of Kemal $(1976,1981)$ also help further in the same direction. With the pooled data, we had 448 observations to estimate the system. Additional data where necessary were obtained from Economic Survey, Monthly Statistical Bulletins, Fifty Years of Pakistan in Statistics, and Statistical Yearbook [Pakistan (1998, 1998a, 1997, 1992)]. To state it briefly, the necessary data from these sources is obtained for prices, values and quantities, stock of capital, total employment, average daily employment and employment costs and material costs.

The following additional variables needed for the analysis were constructed from the available data explained above.

\section{Cost of Production}

Prices and quantities of inputs have been used to compute the cost of production of the given industrial products in the normal way. The Tornqvist Divisia quantity and price indexes are used where aggregation of diverse products was involved. The prices of items like electricity, natural gas (fuel), KO, FO, LDO, HSD, coal (local cum imported) and fuel wood were determined by dividing their values by their quantities. 


\section{User Cost of Capital}

The determination of the user cost of capital requires first the calculation of the stock of capital. We calculate the time series of capital stock from the gross investment time series by using the perpetual inventory method under conditions of constant rate of depreciation. The gross investment time series is derived by adding depreciation to the difference of the values of the fixed assets at the end and the beginning of the year. The constant rate of depreciation used in the perpetual inventory method applied in deriving the time series of gross investment and, thereby, those of the capital stock are obtained as a ratio of the total amount of depreciation to the value of fixed assets at the beginning of the year. The procedure of constructing the capital stock time series is expressed symbolically as

$$
K_{t}=(1-\delta) \quad K_{t-1}+G I_{t-1}
$$

where $K_{t}$ denotes the capital stock in time period $t, G I$ the gross investment and $\delta$ the rate of depreciation. The series for the capital stock and for that matter for all other related variables have been derived from 1969-70 onwards to 1990-91. The user cost of capital, after deriving the series of the capital stock, has been determined with the procedure expressed below.

$$
P_{k}=P_{m}\left(\gamma+\delta-\pi_{m}\right)
$$

where $P_{k}$ is the user cost of capital, $P_{m}$ is the price index of the capital goods, $\gamma$ is the real interest rate, $\delta$ is the depreciation rate and $\pi_{m}$ is the rate of growth of the price index of capital. Thus, the variable representing the user cost of capital is an increasing function of the price of capital, real rate of interest and depreciation rate, and a decreasing function of the appreciation of the value of the capital.

The price of machinery, which is an important variable of the above mentioned function, is not available directly from the CMIs. It is obtained from the Monthly Statistical Bulletins in which machinery price is given as the same across provinces. The interest rate, which is the long-run scheduled bank rate, is also obtained from these Bulletins.

\section{Determination of Wages}

The wages of the industrial workers have been found by dividing the total employment cost by the number of workers employed daily both of which are recorded in CMIs. The values thus obtained are converted into an index indicating the price of labour.

\section{Real Output Value}

The real value of the industrial output has been found by dividing the value of production with the wholesale price index of the manufacturing goods. To this end, the 
data on the value of the industrial output production are taken from the CMIs while those on wholesale prices are collected from the Monthly Statistical Bulletins.

\section{ESTIMATION AND RESULTS}

The required price elasticities are derived by estimating the translog profit function and the related profit share equations with iterative Zellner's efficient method of seemingly unrelated regressions. For the linear regression models, as in our case, this method is asymptotically equivalent to the maximum likelihood method upon convergence. In order to accommodate the adding-up restrictions, one profit share equation was dropped while estimating the system. Since the system is linear in parameters, all the parameters and their standard errors remain independent of the equation that is dropped from direct estimation. Although the parameters of this Equation can be derived from the restrictions in Equations (4), (5) and (6), their standard errors cannot be retrieved in this manner. To obtain the standard errors we use a procedure which takes the Taylor series expansion. The system is re-estimated by including the profit share equation that was dropped and dropping instead another profit share equation.

The estimated system is first examined for the monotonicity and curvature conditions (7) and (8) for it to yield theoretically consistent results. The results show that all the estimated shares are positive and therefore the profit function satisfies the monotonicity property. The curvature condition on the profit function is, however, violated at certain places particularly in case of minor inputs like firewood and coke as shown below.

Most of the parameters have been found statistically significant at the 5 percent level of significance. Since the translog profit function is a flexible function, its parameters do not have direct interpretation. Therefore, it is desirable that we move directly to the estimated own and cross price elasticities depicted in Table 1. Its figures show that the elasticities of input demands are mostly negative, while the elasticity of output supply is positive. Though the elasticities for firewood and coke are positive, but none of them is statistically significant even at a high level of significance. These 'wrong' signs can, therefore be attributed to sampling error. The inputs for which the own elasticities are negative but insignificant include capital, kerosene oil, light diesel oil and petrol.

For detailed analysis, we now classify all the energy inputs into four categories, namely, coal/firewood, petroleum products, natural gas and electricity. As mentioned above, some elasticities of demand in the coal/firewood category are positive but insignificant. These inputs are least important in terms of their shares in the total cost of production and are likely to be used in limited amounts. Given the observation that over time the inputs like petroleum products, natural gas and electricity have replaced the traditional energy inputs, one can expect that firewood and coke are left for very specific uses. Therefore, the demand for these inputs is expected to be price inelastic. Coal and charcoal are the major inputs in this category and their demand, especially that 
Table 1

Own Price Elasticities of Energy Products

\begin{tabular}{lcc}
\hline Variable & Estimates & $t$-statistics \\
\hline Capital & -1.2182 & -0.35 \\
Labour & -0.836 & -1.97 \\
Fire wood & 0.317 & 0.65 \\
Coal & -1.7732 & -3.84 \\
Coke & 0.0126 & 0.03 \\
Charcoal & -0.5916 & -2.16 \\
Kerosene Oil & -0.0166 & -0.07 \\
Furnace Oil & -0.9486 & -29.07 \\
HSDO & -1.1053 & -59.38 \\
LDO & -0.0934 & -0.28 \\
Petrol & -0.0799 & -0.18 \\
Natural Gas & -1.085 & -18.73 \\
Electricity & -1.44 & -22.47 \\
Output & 12.0541 & 18.29 \\
\hline
\end{tabular}

of coal, is relatively more sensitive to price changes. There may be a need to discourage excessive burning of wood for charcoal because of its adverse implications for rapid depletion of wood resources in the country. The depletion of wood forests is potentially injurious to the entire ecology of the country. The needed and effective policy intervention may be to change the price regime against charcoal especially to stimulate its substitution for mineral energy sources or to electricity.

In the petroleum products group, all the own price elasticities of demand are negative but their magnitudes differ substantially from one another. Specifically, the elasticity of demand for high-speed diesel oil exceeds the benchmark value of unity and that of furnace oil is close to one, while those of the remaining three inputs, kerosene oil, light diesel oil and petrol are both quite low and statistically insignificant. Thus, the general perception that demand for petroleum products is inelastic does not seem to be true for all of them. For example, the demand for high speed diesel is found to be elastic. On the whole, these products appear to be elastically demanded. As such, the increase in prices of the petroleum products needs to be mediated carefully because the economic advancement of the society is being accompanied by its increased dependence on energy-consuming goods especially transportation. Further, since a given increase in their prices will cause a substantial decrease in their demand, output is expected to decrease accordingly with its adverse impact permeating the whole network of production, distribution and marketing of industrial products in the country.

The estimated own price elasticities for the remaining two categories of energy inputs, namely, natural gas and electricity are greater than one and statistically significant. Although estimates appear to be rather too large, they are close to the ones obtained by Idrees (1997) from a six-input Generalised Leontief cost function but less 
than those obtained from translog cost function. The results in Idrees (1997) also suggest that the demand for electricity is price elastic, despite the observed increase in its consumption.

There are at least two possible explanations for the high estimates of elasticities. First, during the period of 1980s, when the severe energy shortage led to wide-scale load shedding, the manufacturing sector looked for various options to cope with the rationing. It is quite likely that over the years firms might have learnt to adopt electricity conserving production processes. ${ }^{7}$

Another explanation, that is at least as plausible as the first one, is that the increased incidence of power theft may have significantly eroded the data on quantity and cost of electricity consumption, thereby distorting the elasticity estimates. The same argument may also apply to the high estimate for the elasticity of demand for natural gas.

Nevertheless, the above estimates of elasticity can still be useful for policy purposes as they represent the observed data. In particular, if the level of distortion remains the same as it exists, it is the observed elasticity, (also referred to as buoyancy) rather than the true underlying elasticity that is practically relevant. The fact that both natural gas and electricity are elastically demanded have policy implications. Frequent increases in their prices seem arguably to exercise adverse effect on the production of industrial goods. They also serve to encourage producers to search for cheap substitutes or improved measures of conservation.

We now move to the cross elasticity estimates, which are presented in Table 2. Although all the cross elasticities are presented in this Table, it is perhaps not useful to comment on each of them. We shall discuss the cross elasticities for energy inputs and only the ones that are significantly different from one.

In the coal/firewood category, the cross elasticities are generally insignificant. As expected for firewood, none of the cross elasticities is statistically significant. Almost the same is the case with coal, except that it is found to be a substitute for petrol. Similarly, the cross elasticities of demand for coke are also insignificant except that its elasticity of demand with respect to the price of firewood is positive while the elasticity with respect to the price of light diesel oil is negative and both the elasticities are somewhat significant. Thus, coke appears to be a weak substitute for firewood and complement to light diesel oil simultaneously. Finally, charcoal is found to be a substitute for coke and, to some extent, for natural gas and is complementary to capital.

The cross elasticities in case of petroleum products group are relatively higher than the ones obtained for the coal/firewood category. For example, the demand for kerosene oil appears to be quite sensitive to changes in the prices of most of the other

${ }^{7}$ Using a sample of 60 manufacturing firms in Gujranwala, Ahmad (1995a) has shown that the firms could recover a substantial portion of potential loss from load shedding by using their own power generators and restoring to overtime work and process re-adjustment. 
Table 2

Own and Cross Price Elasticities

\begin{tabular}{|c|c|c|c|c|c|c|c|c|c|c|c|c|c|c|}
\hline \multirow[b]{2}{*}{ Variables } & \multicolumn{14}{|c|}{ Own and Cross Price Elasticities } \\
\hline & Capital & Charcoal & Coal & Coke & Electricity & $\begin{array}{c}\text { Fire } \\
\text { Wood }\end{array}$ & Furnace Oil & HSDO & $\begin{array}{c}\text { Kerosene } \\
\text { Oil }\end{array}$ & Labour & LDO & $\begin{array}{c}\text { Natural } \\
\text { Gas }\end{array}$ & Petrol & Output \\
\hline \multirow[t]{2}{*}{ Capital } & -0.375 & 0.001 & 0.008 & 0.011 & 0.003 & 0.001 & -0.082 & -0.002 & 0.001 & 0.475 & 0.002 & 0.125 & 0.015 & 0.535 \\
\hline & $(-0.10)$ & $(1.22)$ & (1.16) & (1.46) & $(0.01)$ & $(0.69)$ & $(-5.27)$ & $(-0.26)$ & $(0.43)$ & $(0.45)$ & $(0.71)$ & $(1.60)$ & $(1.10)$ & $(0.28)$ \\
\hline \multirow[t]{2}{*}{ Charcoal } & -4.403 & -0.592 & -3.654 & 1.208 & 0.569 & 0.835 & -2.320 & -0.904 & 5.480 & -0.667 & -4.470 & 1.957 & -1.387 & 8.336 \\
\hline & $(-1.64)$ & $(-2.16)$ & $(-1.44)$ & (2.01) & $(0.34)$ & $(1.28)$ & $(-1.51)$ & $(-0.66)$ & (1.41) & $(-0.86)$ & $(-1.50)$ & (1.59) & $(-1.18)$ & (1.27) \\
\hline \multirow[t]{2}{*}{ Coal } & -3.878 & -0.370 & -1.773 & 0.537 & -1.474 & 0.609 & -0.592 & 0.486 & -0.868 & 0.609 & -0.576 & 0.366 & 1.333 & 5.579 \\
\hline & $(-1.39)$ & $(-1.55)$ & $(-3.84)$ & (1.11) & $(-1.17)$ & $(1.33)$ & $(-1.05)$ & $(1.07)$ & $(-0.26)$ & $(0.39)$ & $(-0.62)$ & $(0.79)$ & $(1.85)$ & $(0.86)$ \\
\hline \multirow[t]{2}{*}{ Coke } & 8.408 & -0.179 & -0.786 & 0.013 & 1.832 & 0.411 & -0.915 & 0.703 & 0.693 & -0.456 & -0.486 & 0.774 & -0.364 & -9.660 \\
\hline & (1.26) & $(-1.30)$ & $(-1.26)$ & $(0.03)$ & $(1.15)$ & $(1.71)$ & $(-1.43)$ & (1.39) & (1.45) & $(-0.61)$ & $(-1.76)$ & $(1.25)$ & $(-1.01)$ & $(-0.82)$ \\
\hline \multirow[t]{2}{*}{ Electricity } & 0.034 & -0.001 & 0.034 & 0.029 & -1.440 & 0.007 & -0.027 & 0.014 & -0.031 & -0.224 & -0.011 & -0.412 & -0.024 & 2.040 \\
\hline & $(0.02)$ & $(-0.39)$ & $(1.32)$ & (1.69) & $(-22.47)$ & $(1.76)$ & $(-0.54)$ & $(0.93)$ & $(-2.89)$ & $(-0.53)$ & $(-2.17)$ & $(-4.06)$ & $(-1.40)$ & $(0.37)$ \\
\hline \multirow[t]{2}{*}{ Fire Wood } & 5.968 & 1.766 & -12.726 & 5.870 & 6.282 & 0.317 & -3.486 & -2.719 & 8.964 & 3.738 & -4.878 & 4.673 & -6.125 & 0.498 \\
\hline & $(0.47)$ & $(0.83)$ & $(-0.87)$ & $(0.85)$ & $(0.69)$ & $(0.65)$ & $(-0.86)$ & $(-0.71)$ & $(0.85)$ & $(0.95)$ & $(-0.85)$ & $(0.87)$ & $(-0.84)$ & $(0.04)$ \\
\hline \multirow[t]{2}{*}{ Furnace Oil } & -4.362 & 0.024 & 0.061 & -0.064 & 0.123 & -0.017 & -0.949 & -0.044 & -0.065 & -0.740 & 0.024 & -0.063 & 0.025 & 6.605 \\
\hline & $(-2.44)$ & (3.26) & $(1.00)$ & $(-1.59)$ & $(0.52)$ & $(-2.07)$ & $(-29.1)$ & $(-1.45)$ & $(-2.43)$ & $(-1.96)$ & (2.25) & $(-0.54)$ & $(0.77)$ & (1.31) \\
\hline \multirow[t]{2}{*}{ HSDO } & -0.461 & 0.052 & -0.276 & 0.272 & 0.335 & -0.074 & -0.244 & -1.105 & -0.081 & 0.259 & -0.169 & 0.195 & -0.079 & 1.200 \\
\hline & $(-0.24)$ & $(0.92)$ & $(-1.19)$ & (1.95) & $(0.92)$ & $(-1.47)$ & $(-1.41)$ & $(-59.38)$ & $(0.54)$ & $(0.64)$ & $(-2.10)$ & (1.05) & $(-0.48)$ & $(0.22)$ \\
\hline
\end{tabular}


Table 2-(Continued)

\begin{tabular}{|c|c|c|c|c|c|c|c|c|c|c|c|c|c|c|}
\hline \multirow[b]{2}{*}{ Variables } & \multicolumn{14}{|c|}{ Own and Cross Price Elasticities } \\
\hline & Capital & Charcoal & Coal & Coke & Electricity & $\begin{array}{c}\text { Fire } \\
\text { Wood }\end{array}$ & Furnace Oil & HSDO & $\begin{array}{c}\text { Kerosene } \\
\text { Oil }\end{array}$ & Labour & LDO & $\begin{array}{c}\text { Natural } \\
\text { Gas }\end{array}$ & Petrol & Output \\
\hline \multirow[t]{2}{*}{ Kerosene Oil } & -0.881 & -0.739 & 1.156 & 0.631 & -1.817 & 0.572 & -0.839 & 0.190 & -0.017 & 2.308 & -0.435 & 1.095 & -0.419 & -2.179 \\
\hline & $(-0.41)$ & $(-3.56)$ & $(2.21)$ & (2.26) & $(-3.26)$ & (3.39) & $(-2.44)$ & $(0.54)$ & $(-0.07)$ & (2.14) & $(-1.99)$ & (2.66) & $(-1.24)$ & $(-0.34)$ \\
\hline \multirow[t]{2}{*}{ Labour } & 1.434 & 0.001 & -0.004 & -0.002 & -0.057 & -0.001 & -0.042 & 0.003 & 0.010 & -0.836 & 0.002 & -0.023 & 0.006 & 0.513 \\
\hline & $(0.51)$ & $(0.66)$ & $(-0.49)$ & $(-0.55)$ & $(-0.52)$ & $(-1.67)$ & $(-2.09)$ & $(0.65)$ & (2.43) & $(-1.97)$ & (1.12) & $(-0.41)$ & $(0.98)$ & $(0.14)$ \\
\hline \multirow[t]{2}{*}{ LDO } & 1.781 & 0.861 & 1.095 & -0.631 & -0.903 & -0.444 & 0.439 & -0.565 & -0.419 & 0.521 & 0.093 & -0.607 & 0.927 & -1.957 \\
\hline & $(0.94)$ & (2.94) & (2.59) & $(-2.68)$ & $(-2.64)$ & $(-3.02)$ & $(1.91)$ & $(-1.89)$ & $(-1.23)$ & $(1.05)$ & $(0.28)$ & $(-3.11)$ & (2.52) & $(-0.31)$ \\
\hline \multirow[t]{2}{*}{ Natural Gas } & -1.818 & -0.006 & -0.010 & 0.015 & -0.507 & 0.006 & -0.017 & 0.010 & 0.023 & -0.112 & -0.009 & -1.085 & 0.013 & 3.485 \\
\hline & $(-0.99)$ & $(-3.75)$ & $(-0.72)$ & (1.59) & $(-3.72)$ & (3.03) & $(-0.55)$ & (1.14) & (3.18) & $(-0.39)$ & $(-4.49)$ & $(-18.73)$ & (1.02) & $(0.71)$ \\
\hline \multirow[t]{2}{*}{ Petrol } & 3.793 & 0.068 & -0.650 & -0.121 & -0.521 & -0.143 & 0.119 & -0.067 & -0.153 & 0.538 & 0.237 & 0.219 & -0.080 & -3.252 \\
\hline & (1.32) & (1.17) & $(-1.71)$ & $(-1.10)$ & $(-1.65)$ & $(-1.93)$ & $(0.65)$ & $(-0.47)$ & $(-1.09)$ & $(0.82)$ & (1.87) & $(0.83)$ & $(0.18)$ & $(-0.43)$ \\
\hline \multirow[t]{2}{*}{ Output } & 0.304 & 0.001 & 0.006 & 0.007 & -0.098 & -0.000 & -0.070 & -0.002 & 0.002 & 0.096 & 0.001 & -0.136 & 0.730 & 12.054 \\
\hline & $(0.23)$ & (1.33) & $(0.96)$ & $(0.71)$ & $(-0.45)$ & $(-0.04)$ & $(-4.70)$ & $(-0.25)$ & $(0.29)$ & $(0.12)$ & $(0.27)$ & $(-1.33)$ & $(0.38)$ & (18.29) \\
\hline
\end{tabular}


factor inputs. Kerosene oil is found to be a strong substitute for labour, firewood, coal, coke and natural gas while it is complementary to charcoal, light furnace oil, diesel oil and electricity. Further, furnace oil is found to have a substitutability relationship with charcoal and light diesel oil while it has complementarity with capital, labour, firewood and kerosene oil. The elasticities of demand for high speed diesel oil are quite low and statistically insignificant, the only exception being that it is found to be complementary to light diesel oil. The cross elasticities of demand for light diesel oil, on the other hand, are relatively high and significant. In particular, light diesel oil is found to be a substitute for coal, charcoal, furnace oil and petrol and complementary to firewood, coke, high speed diesel oil, natural gas and electricity. Finally, most of the cross elasticities of demand for petrol are relatively low and statistically insignificant. Petrol is found to be a substitute for light diesel oil and complementary to firewood, coal and electricity. The lack of substitutability of petrol for other energy products ought to be a strong consideration for any relevant price policy intervention. When no other product can replace it as an alternative source of energy, movements in its price ought to be kept in mind from that perspective.

The results show that the demand for natural gas is generally sensitive to changes in the prices of other energy inputs. In particular, it is found to be substitute for firewood and kerosene oil and complementary to charcoal, light diesel oil and electricity. The cross effects on the demand for electricity are relatively less significant. The results suggest that electricity is a weak substitute for firewood and coke while it forms a complementarity relationship with kerosene oil, light diesel oil and natural gas. As such, constant efforts need to be made to increase the supply of natural gas through new discoveries. Abundant supply of cheap natural gas will definitely reduce the cost of production and thereby the consumer prices if the benefit of the low production cost is transferred down to them.

It should be noted that none of the inputs is found to have significant elasticity of demand with respect to output price. The elasticities of demand for energy with respect to capital rental rate and wage rate are mostly insignificant. Interestingly, the cross elasticities of demand for both capital and labour with respect to the prices of energy inputs are also mostly insignificant. On the other hand, except for the coke/firewood category, within the group of energy inputs, quite a large number of cross elasticities of demand are significant. This conclusion is also consistent with our earlier results that demands for energy inputs are generally sensitive to changes in their own prices. The results also suggest that the prospects for inter-fuel substitution are much better than for the intra-fuel substitution. Thus, change in the price of an energy input is more likely to be absorbed by reallocation of resources across energy inputs rather than across energy and non-energy inputs.

\section{SUMMARY AND CONCLUSIONS}

This study has estimated the industrial sector input demand elasticities for eleven products separately at the disaggregated level by estimating a flexible translog profit 
function and the related share equations with the iterative Zellner's efficient method of seemingly unrelated equations in a demand system after examining its monotonicity and curvature conditions. The input demand elasticities of the energy products considered are mostly negative as expected. Viewed from policy perspective, the demand for coal, charcoal from the coal/firewood category is fairly sensitive to price. Similarly, in the petroleum products group, the demand for HSDO is price elastic and the elasticity of demand for furnace oil is also close to one. For the remaining three inputs of kerosene oil, light diesel oil and petrol, the elasticities are quite low. Thus, the pricing policy, especially in respect of petroleum products, must be carefully formulated because the general impression of their demand to be inelastic does not seem to be true. However, the elasticitity of natural gas and electricity are highly significant implying that the degree of responsiveness of the quantities demanded is disproportionately greater than a given percentage change in their prices.

Petrol has shown minimal substitution for other energy products, whereas furnace oil has shown a substitutability relationship with charcoal and light diesel oil and a complementarity relationship with capital, labour, firewood and kerosene oil. Except for the coke/firewood category within the group of energy inputs, a large number of cross elasticities of demand are significant and thus input demands appear to be sensitive to changes in prices of other related inputs. It appears that the prospects for inter-fuel substitution are much better than for intra-fuel substitution. Thus, changes in the price of an energy input are more likely to be absorbed in reallocation of resources across energy inputs rather than between energy and non-energy inputs. As such, the values of own and cross price elasticities of demand for various inputs may point to the probable impact of any price-tax-subsidy policy intervention.

\section{REFERENCES}

Ahmad, Eatzaz (1988) Consumption and Work Hours in the Life Cycle Models with Uncertain Lifetimes: An Individual Analysis and an Equilibrium Analysis with Overlapping Generations. Ph. D. Thesis. McMaster University, Hamilton, Canada.

Ahmad, Eatzaz (1995) Economic Analysis of Privately Owned Power Generators in Small Scale Manufacturing Firms. The Fifth International Conference on Business and Economic Development in Middle-Eastern and Mediterranean Countries. Papers and Proceeding, Sydney.

Ahmad, Eatzaz (1995a) Power Shortages and Economic Losses in Small and Medium Sized Manufacturing Firms of Gujranwala (Pakistan). The University of Newcastle, Callaghan, Australia. (Occasional Paper.)

Battese, G. E., and S. J. Malik (1987) Estimation of Elasticities of Substitution for CES Production Function Using Data on Selected Manufacturing Industries. The Pakistan Development Review 26:2.

Browning, M. J., A. Deaton, and M. Irish (1985) A Profitable Approach to Labour Supply and Commodity Demands Over the Life Cycle. Econometrica 53: 503-43. 
Christensen, L.R., D. W. Jorgenson, and L. J. Lau (1971) Conjugate Duality and the Transcendental Logarithmic Production Function. Econometrica 39:4 255-56.

Deaton, A., and J. Muellbauer (1980) An Almost Ideal Demand System. American Economic Review 70: 312-326.

Diewert, W. E. (1973) Functional Forms for Profit and Transformation Functions. Journal of Economic Theory 6.

Diewert, E. (1974) Application of Duality Theory. In M. Intriligator and D. Kendrick (eds) Frontiers in Quantitative Economics. Amsterdam: North-Holland.

Diewert, W. E. (1976) Exact and Superlative Index Numbers. Journal of Econometrics 4:2.

Frisch, R. (1932) New Methods of Measuring Marginal Utility. J. C. B. Mohr, Tubigen.

Gotsch, Carl H. (1976) Relationships of Technology, Prices and Income Distribution in Pakistan's Agriculture: Some Observations on the Green Revolution in Robert D. Stevens (eds) Rural Development in Bangladesh and Pakistan. Honolulu: the University Press of Hawaii.

Pakistan, Government of (1992) Economic Survey 1991-92. Islamabad: Economic Adviser's Wing.

Pakistan, Government of (Various Issues) Statistical Yearbook. Islamabad: Federal Bureau of Statistics.

Pakistan, Government of (Various Issues) Census of Manufacturing Industries. Ministry of Industries.

Pakistan, Government of (Various Issues) Monthly Statistical Bulletin. State Bank of Pakistan.

Pakistan Government of (n.d.) Fifty Years of Pakistan in Statistics. Islamabad: Federal Bureau of Statistics.

Houthakkar, J. J. (1960) Additive Preferences. Econometrica 28: 244-56.

Idrees, M. (1997) Production Relations in the Manufacturing Sector of Pakistan. M. Phil. Thesis, Department of Economics, Quaid-i-Azam University, Islamabad.

Kemal, A. R. (1976) Sectoral Growth Rates and Efficiency of Factor Use in Large-scale Manufacturing Sector in West Pakistan. The Pakistan Development Review 15:3 248-281.

Kemal, A. R. (1981) Substitution Elasticities in the Large-scale Manufacturing Industries of Pakistan. The Pakistan Development Review 20:1.

Khan, Mahmood-ul-Hasan (1998) Allocative Efficiency in the Manufacturing Sector of Pakistan, unpublished M. Phil. Thesis, Department of Economics, Quaid-i-Azam University, Islamabad.

Malik, J. S., M. Mushtaq, and H. Nazli (1989) An Analysis of Production Relations in the Large-Scale Manufacturing Sector of Pakistan. The Pakistan Development Review 28:1 27-42.

McFadden (1978) Cost, Revenue and Profit Functions. In M. Fuss and D. McFadden (eds) Production Economics: A Dual Approach to Theory and Applications. Amsterdam: North-Holland.

Varian, H. R. (1992) Microeconomic Analysis. Third Edition. New York: W. W. Norton and Company. 


\section{Comments}

The authors have made an excellent effort to estimate the manufacture's demand for different energy inputs such as electricity, natural gas, petro-products, coak and coal, and firewood along with labour and capital. Relying on the data of 16 years from 1969-70 to 1990-91, they used the translog profit function and the related share equations in the exercise. They have also reported using the 1997 price data, stock of total capital, total employment and the material cost from Economic Survey and Monthly Statistical Bulletins etc. The authors derived the price elasticities by estimating the translong profit function and the related share equations with Zellener's efficient method of seemingly unrelated equations. For theoretical consistency they examined the estimated system for the monotonocity and curvature conditions. The demand for coal/charcoal from coal or firewood is found fairly sensitive to price. The results show that the input demand elasticities are mostly negative. For detailed analysis they classified all the energy inputs into four categories, namely coal/firewood, petroleum products, natural gas and electricity. The demand for coal/charcoal from coal or firewood is found fairly sensitive to price. In the petroleum products group, all the own price elacticities of demand are negative but substantial difference is reported from one to the other. For petroleum products group the elasticities of HSDO and furnace oil are reported near to 1. For kerosene oil, light diesel oil and petrol the elasticities are reported to be low. The estimated elasticity of natural gas and electricity are greater than one and substantially significant.

Though the paper has few deficiencies, I feel that there is some room for improvement in it. Nowhere in the paper the study has mentioned about the explained variation in the regression model. The authors should have mentioned the adjusted $\mathrm{R}^{2}$ to let the reader know about the explained variation in the dependent variable caused by the independent variables. The authors have used the data since 1969-70 and have used nominal prices without taking into consideration the inflation from 1969-70 onward. In the absence of real prices the results of the study may portray a picture, which may be far from reality. The authors have conducted the analysis on industrial sector input demand response by aggregating the various domestic industrial sectors. The study may lead to a better policy recommendation if different industries are desegregated into various sectors such as textile industry, steel industry etc. and then conducting the analysis separately. Although it will be complicated to go into such an analysis but, for the perception of a realistic picture, I feel it needs to be done.

I hope these suggestions will help the authors to improve the quality of the paper.

International Water Management Institute,

Waqar A. Jehangir Lahore. 